\title{
ANÁLISE GEOGRÁFICA DE ÁREAS DE RISCO DE MOVIMENTO DE MASSA NA REGIÃO METROPOLITANA DE PORTO, PORTUGAL
}

\author{
Luis Eduardo de Souza Robaina \\ Av. Roraima 1000 - Universidade Federal de Santa Maria - Departamento de Geociências - CEP 97.105-900 - \\ Santa Maria - Rio Grande do Sul - Brasil - Faculdade de Letras da Universidade do Porto - Via Panorâmica s/ $n^{\circ}$. 4150- \\ 564 Porto - Portugal-e-mail: lesrobaina@yahoo.com.br \\ Antonio de Sousa Pedrosa \\ Av. Roraima 1000 - Universidade Federal de Santa Maria - Departamento de Geociencias - CEP 97.105-900 - \\ Santa Maria - Rio Grande do Sul - Brasil - Faculdade de Letras da Universidade do Porto - Via Panorâmica s/n. 4150- \\ 564 - Porto - Portugal - e-mail: aspedros@gmail.com
}

Thiago Bazzan

Instituto de Geociências - Programa de Pós-graduação em Geografia - UFRGS - Av. Bento Gonçalves, 9500. Prédio 43113 - Sala 203 - Campus do Vale - CEP 91.501900 - Porto Alegre/RS - Brasil

Elisabete Weber Reckziegel

Instituto de Geociências - Programa de Pós-graduação em Geografia - UFRGS - Av. Bento Gonçalves, 9500. Prédio 43113 - Sala 203 - Campus do Vale - CEP 91.501900 - Porto Alegre/RS - Brasil

\begin{abstract}
Resumo
Este trabalho estabelece uma discussão de áreas sujeitas a risco de acidentes desencadeados por movimentos de massa na Serra do Pilar, em Vila Nova de Gaia, Porto, Portugal. O mapa base para a análise foi a planta topográfica de Vila Nova de Gaia, em escala de 1:2000 e as imagens disponíveis no software Google Earth. As análises foram realizadas por meio de trabalhos de campo, em que foram percorridas as vias de acesso da comunidade e descritas as características das habitações (material construtivo, acabamento, tamanho e obras de contenção) e as feições do terreno que indicam susceptibilidade a movimentos de massa. Para determinar a localização das observações de campo e das moradias em situação de risco utilizou-se um receptor do Global Positioning System (GPS). Para o georreferenciamento e edição vetorial da planta topográfica e imagens utilizou-se o SPRING 4.2. Na elaboração do Modelo Digital do Terreno (MDT) foi utilizado o aplicativo Surfer 8.0. A edição final dos mapas foi realizada no programa gráfico Corel Draw. As habitações são constituídas de alvenaria com variado nível de acabamento. Ocorrem duas situações em termos de susceptibilidade a movimentos de massa: uma porção onde ocorre a exposição de rochas em declives muito acentuados e outra porção onde ocorre uma concentração do fluxo da água com desenvolvimento de um solo/alterito que permite a fixação de vegetação. Verifica-se pelo menos seis patamares de corte na frente e atrás das moradias. Estes cortes juntamente com o acúmulo de água pluvial e de esgoto, a presença de entulhos, muros e pequenas construções podem se constituir em indutores da ocorrência de processos na vertente. As situações mais graves ocorrem onde o adensamento das ocupações é maior, na porção Centro-Leste. Para a redução dos riscos é necessário a execução de um plano de intervenções estruturais voltado para a redução ou a erradicação dos riscos, concomitante com uma intervenção junto à comunidade, buscando formas de organização comunitária e participativa nos projetos de monitoramento permanente e prevenção de acidentes.
\end{abstract}

Palavras-chave: Área de risco; dinâmica de encosta; movimentos de massa; cidade do Porto, Portugal. 


\begin{abstract}
The present work establishes a discussion about the areas under risk of accidents by mass-wasting in Serra do Pilar, located in the Vila Nova de Gaia - Portugal. The analysis base was the topographic map of Vila Nova de Gaia in scale of 1:2000 and images available on Google Earth software. The analyzes have been accomplished through field works by access of the community with describing the houses' characteristics (construction material, finishing work, size, and contention works) as well as the area features indicating susceptibility to mass-wasting. To determine the location of field observations and of the houses at risk, we used a recipient of the Global Positioning System (GPS). For the georeferencing and vectorial edition of the topographic map and images, we have applied the SPRING 4.2, while for the elaboration of the Digital Terrain Model (DTM) the applicative applied was the Surfer 8.0. The final edition of the maps has been accomplished in the Corel Draw graphic program. The houses are made of masonry showing an assorted level of finishing work. One can observe two situations regarding the susceptibility to mass-wasting: a portion with the occurrence of rocks exposure in highly accentuated declines and other portion where occurs a concentration of the water flow with the development of a soil/alterite which allows the vegetation fixing. At least six cut landings are verified in the back and front of the houses. Such cuts, together with the saturation of regolith with pluvial water and sewer accumulation, may act as conductors of the occurrence of processes in the slope. The most serious situations occur where the thickening of the occupations is larger in the center-west region. In order to decrease the risks, it is necessary to carry out a plan of structural interventions addressed to their reduction or erradication in concomitance with the searching for a community organization that may be participative in the projects of permanent monitoring and of accidents prevention.
\end{abstract}

Keywords: Risk area; slope dynamic; Mass-wasting; Porto city, Portugal.

\section{Introdução}

A cidade, conforme Santos (1994), é uma realização humana que vai se constituindo em um longo processo histórico, sendo um produto social onde as aspirações individuais e/ou coletivas estão susceptíveis às decisões político-econômicas.

Dessa forma, diante da complexidade dos fatores e elementos envolvidos, os problemas urbanos devem ser analisados de forma abrangente, sob a ótica natural, sócioespacial e política, pois assumem perfis espaciais diferenciados em face das desigualdades que se acentuam nas áreas urbanas contemporâneas.

Os riscos associados a processos naturais, como os movimentos de massa em encostas, são um dos problemas urbanos que mais têm aumentado nos últimos anos, sobretudo em períodos chuvosos. Estes desastres causam enormes prejuízos à sociedade, pois, em muitos casos, nas proximidades ou sobre a própria encosta, encontram-se habitações, vias, dutos ou qualquer outro elemento componente da infraestrutura da região.

Neste contexto, este trabalho estabelece uma discussão da ocupação irregular em áreas sujeitas a risco de acidentes desencadeados por movimentos de massa na região metropolitana do Porto. Utilizou-se como estudo de caso a comunidade localizada na encosta da Serra do Pilar, em Vila Nova de Gaia, entre as Pontes D. Luis I e D. Infante, entre as coordenadas $41^{\circ} 08^{\prime} 16^{\prime \prime}$ e $41^{\circ} 08^{\prime} 27^{\prime \prime}$ de latitude norte $08^{\circ}$ 36 ' 5" e $08^{\circ} 36^{\prime} 35^{\prime \prime}$ de longitude oeste (Figura 1), abrangendo uma área de $104171 \mathrm{~m}^{2}$.

A Serra do Pilar pertence à Freguesia de Santa Marinha, uma das mais populosas do Concelho de Vila Nova de Gaia. Constitui uma porção da margem esquerda do Rio Douro, representada pelo vale estreito e profundo, com vertentes íngremes e elevadas, visível em toda a área marginal e que se prolonga até à foz. O rio está encaixado em uma falha de direção NNW-SSE, que, segundo Araújo (1985, apud NORONHA, 2005), associa-se à falha Porto-Tomar.

\section{Metodologia}

O mapa base para a análise foi a planta topográfica cedida pela Freguesia de Vila Nova de Gaia, em escala de 1:2000, ano 2001, e as imagens de satélites disponíveis no software Google Earth no período de elaboração do estudo.

A fundamentação teórica para o desenvolvimento do trabalho define risco como a probabilidade de eventos perigosos causarem consequências indesejadas para uma área habitada, transformando um fenômeno natural em desastre (OGURA; MACEDO, 2002).

$\mathrm{O}$ termo risco indicaria a probabilidade de ocorrência de algum dano a uma população, tanto às pessoas, quanto aos seus bens materiais, configurando-se como uma condição potencial de ocorrência de acidente (MINISTÉRIO DAS CIDADES, 2006).

Neste sentido, Veyret (2007) define que o risco é um objeto social, uma vez que este somente se configura na presença de um indivíduo, grupo ou população que o perceba e possa sofrer seus efeitos, ou seja, o risco seria a tradução de um perigo para aquele que habita uma determinada área susceptível à ocorrência de eventos. Para a autora, as sociedades modernas parecem mais vulneráveis a situações de risco devido à forma de interação com o meio, através da prática de atividades desencadeadoras ou aceleradoras de eventos adversos. 


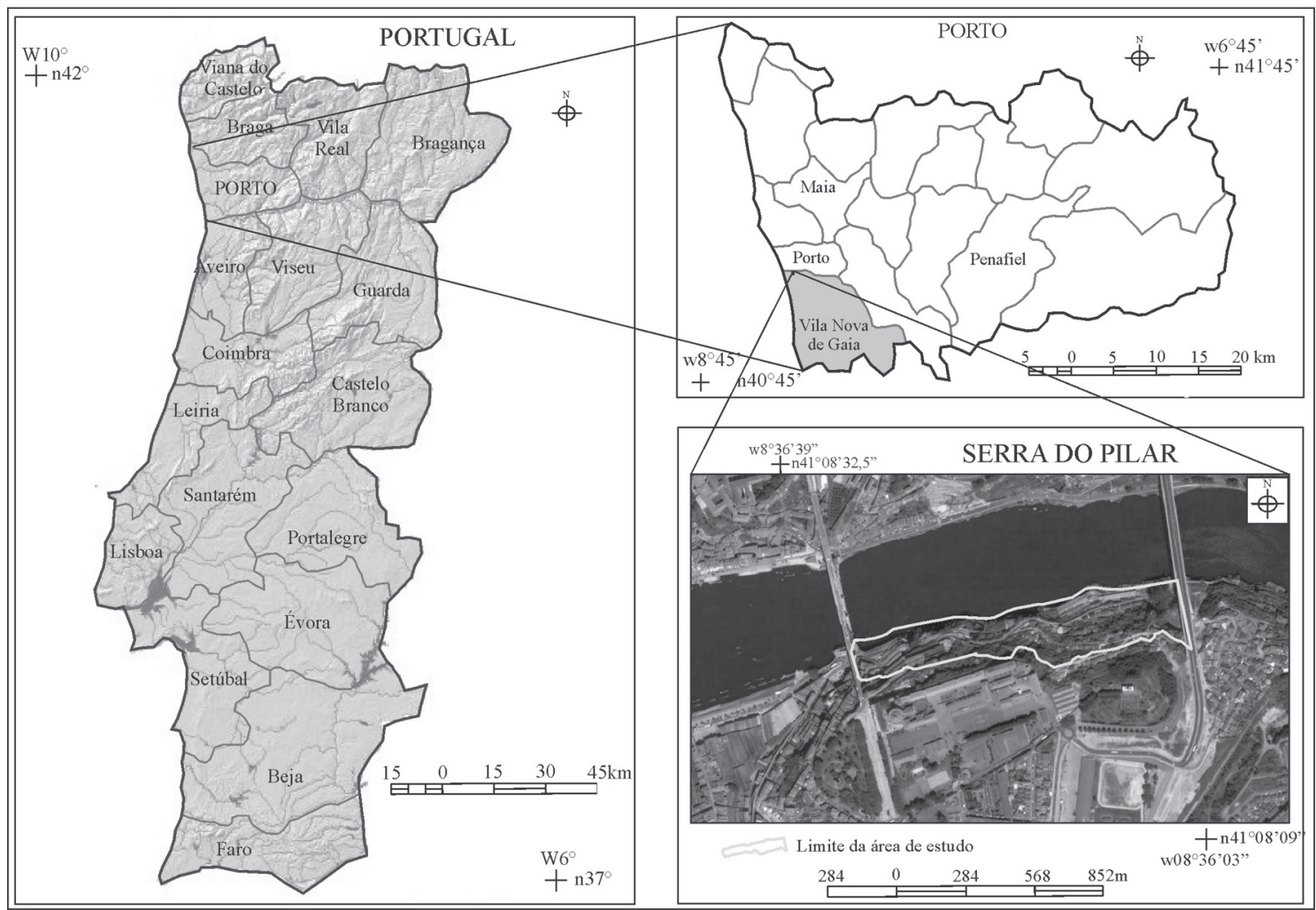

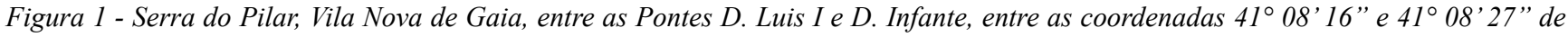
latitude norte $08^{\circ} 36^{\prime} 5^{\prime \prime}$ e $08^{\circ} 36^{\prime} 35^{\prime \prime}$ de longitude oeste.

Sendo assim, quando se trata de risco, deve-se considerar a susceptibilidade à ocorrência de fenômenos e a vulnerabilidade (fragilidade social - densidade demográfica, infraestrutura, conhecimento e percepção do risco, situação econômica, etc.) do sistema que está sob análise (KOBIYAMA et al., 2006).

As análises foram realizadas por meio de trabalhos de campo, em que foram percorridas as vias de acesso da comunidade e descritas as características das habitações (material construtivo, acabamento, tamanho e obras de contenção) e as feições do terreno que indicam susceptibilidade a movimentos de massa. Para determinar a localização das observações de campo e das moradias em situação de risco utilizou-se um receptor do Global Positioning System (GPS).

A susceptibilidade do terreno foi caracterizada através do estudo de feições observadas no campo e na análise da planta topográfica. As principais feições observadas foram: características da vegetação na encosta, erosão laminar indicada por exposição de raízes ou blocos de rocha no solo, parede de rocha fraturada e mergulho das fraturas em relação ao corte, acúmulo de entulhos na encosta inclinada, distância e altura do talude de corte/aterro em relação à moradia, presença de descontinuidade entre solo e rocha, presença de acúmulo de água no terreno, águas servidas lançadas diretamente na encosta e inclinação da encosta.

O georreferenciamento e edição vetorial da planta topográfica da área de estudo foi elaborado no Sistema de
Processamento de Informações Georreferenciadas (SPRING 4.2) desenvolvido pelo Instituto Nacional de Pesquisas Espaciais (INPE). Esse Sistema de Informação Geográfica (SIG) foi concebido inicialmente para apoiar projetos ambientais em grandes bases de dados espaciais (CÂMARA et al., 1996).

A elaboração do Modelo Digital de Terreno (MDT) foi utilizada a partir da aplicação da técnica de interpolação de dados (krigagem) das curvas de nível e pontos cotados da planta topográfica da área de estudo no software Surfer 8 (GOLDEN SOFTWARE, 2002). A edição final dos mapas foi realizada no programa gráfico Corel Draw 12.

\section{Resultados}

\section{Análise da ocupação}

Conforme Matos (1990), a partir dos anos 70, a construção de habitações sob a forma de loteamentos e construções clandestinas assume proporções consideráveis, constituindo uma importante forma de expansão urbana em Portugal. Nos principais centros, essas habitações tomaram grandes proporções. Segundo o autor, estima-se que, entre 1971-1981, 40\% das moradias construídas foram clandestinas ${ }^{1}$.

\footnotetext{
${ }^{1}$ No caso de Portugal, a designação de construção clandestina se dá àquelas feitas sem autorização das câmaras municipais.
} 
Dessa forma, o mercado clandestino de terrenos tem proporcionado o acesso à terra e moradias urbanas a uma população de recursos limitados, servindo como solução habitacional perante a ausência do Estado e a inacessibilidade do mercado privado legal. Esta expansão do mercado clandestino é consequência da formulação de políticas urbanas que favorecem a indústria imobiliária e, de modo mais amplo, aos interesses do setor privado, os efetivos agentes do processo de estruturação do espaço urbano.

O mercado clandestino formado por áreas com ocupações irregulares tem sido importante para os mecanismos econômicos, sociais e políticos, uma vez que proporciona a fixação de abundante mão de obra necessária à expansão dos vários setores da economia. Deste modo, as cidades são constituídas por dois espaços que se justapõe e se complementam, sendo necessários para o modo de produção dominante: um espaço legal e outro irregular e ilegal.
Nessa conjuntura é que ocorre a ocupação da escarpa denominada Serra do Pilar. A expansão urbana na área, conforme relato dos moradores, iniciou-se em 1974, em um processo de ocupação clandestina com pessoas de variadas proveniências e de condições sócioprofissionais diversificadas.

As habitações são constituídas por alvenaria com variado nível de acabamento, desenvolvidas em fases, com base na disponibilidade financeira dos ocupantes e não em um projeto construtivo.

A imagem da área (Figura 2) permite observar a forma desorganizada da ocupação nos patamares da encosta. A diversidade de tipologias e usos caracterizado por habitações unifamiliares, pequenas construções multifamiliares, pequenos comércios e oficinas, além de indústrias desativadas e canteiros com pequenas plantações, é consequência direta de ocupações sem planejamento do conjunto, realizadas em diversas etapas.

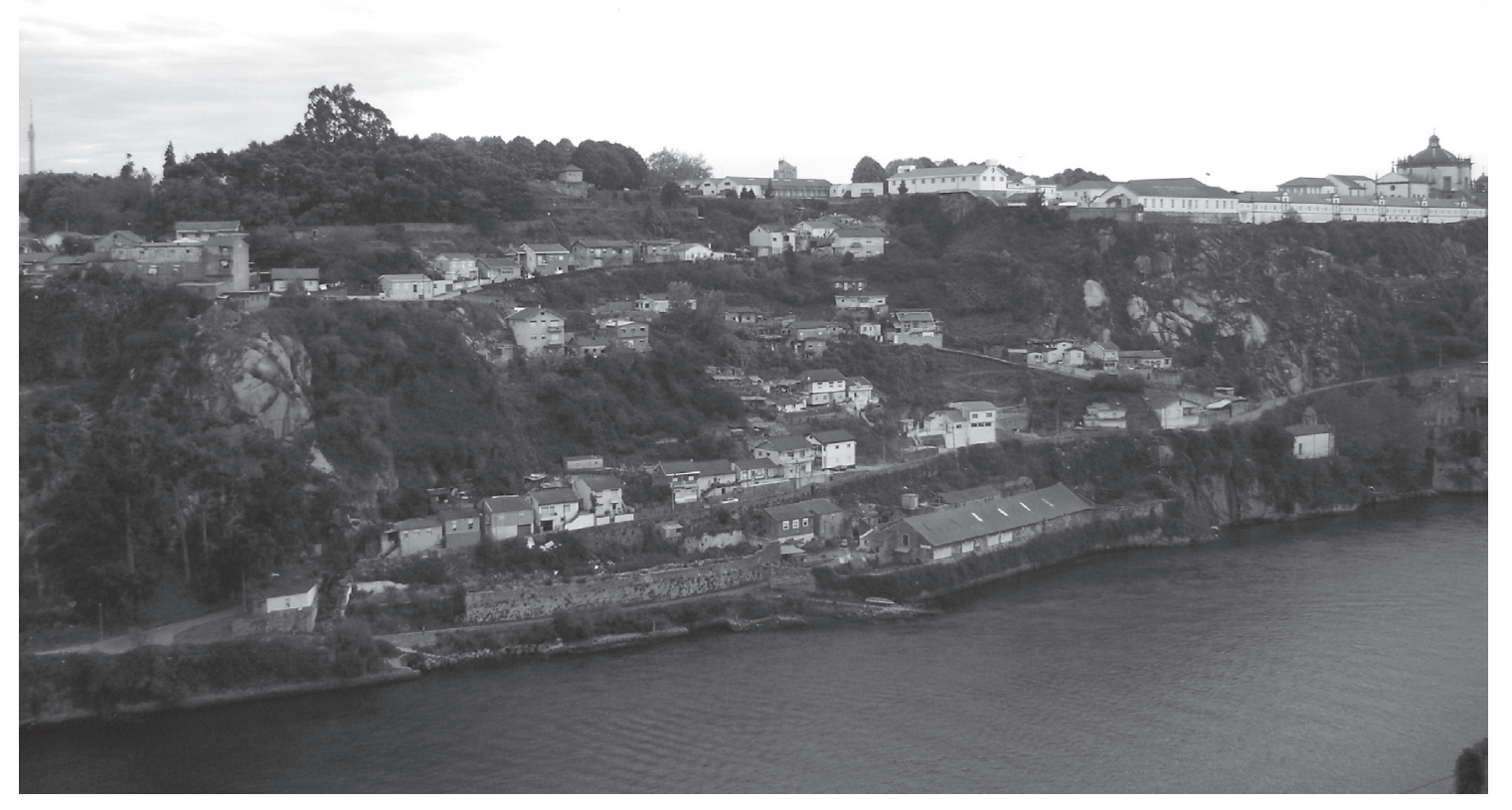

Figura 2 - Fotografia apresentando a forma desorganizada de ocupação da encosta, (Fonte: Trabalho de Campo, 2008).

Destaca-se, ainda, que os habitantes adquiriram os terrenos há mais de 20 anos, significando uma fixação da população ao lugar, devido aos vínculos estabelecidos.

\section{Caracterização da encosta}

A encosta está situada entre 5 e 90 metros de altitude apresentando amplitude de 85 metros com vertentes íngremes e declividades elevadas onde encontram-se as moradias e algumas ruas e caminhos de passagem, conforme pode ser observado na Figura 3.
O substrato é formado por um maciço granítico leucocrático constituído por quartzo, feldspato potássico, predominando sobre os plagioclásios, duas micas (biotita e muscovita), com abundante presença de muscovita. A textura pode ser definida como fanerítica média a grossa, sem presença de lineamentos mineralógicos marcantes. Este substrato formado por um granito de duas micas é chamado Granito do Porto, constituindo as fases de granitogênese ocorridas, conforme Noronha (2005) em torno de 310 M.a. do evento orogênico Hercínico do Carbonífero (360-286 M.a.). 


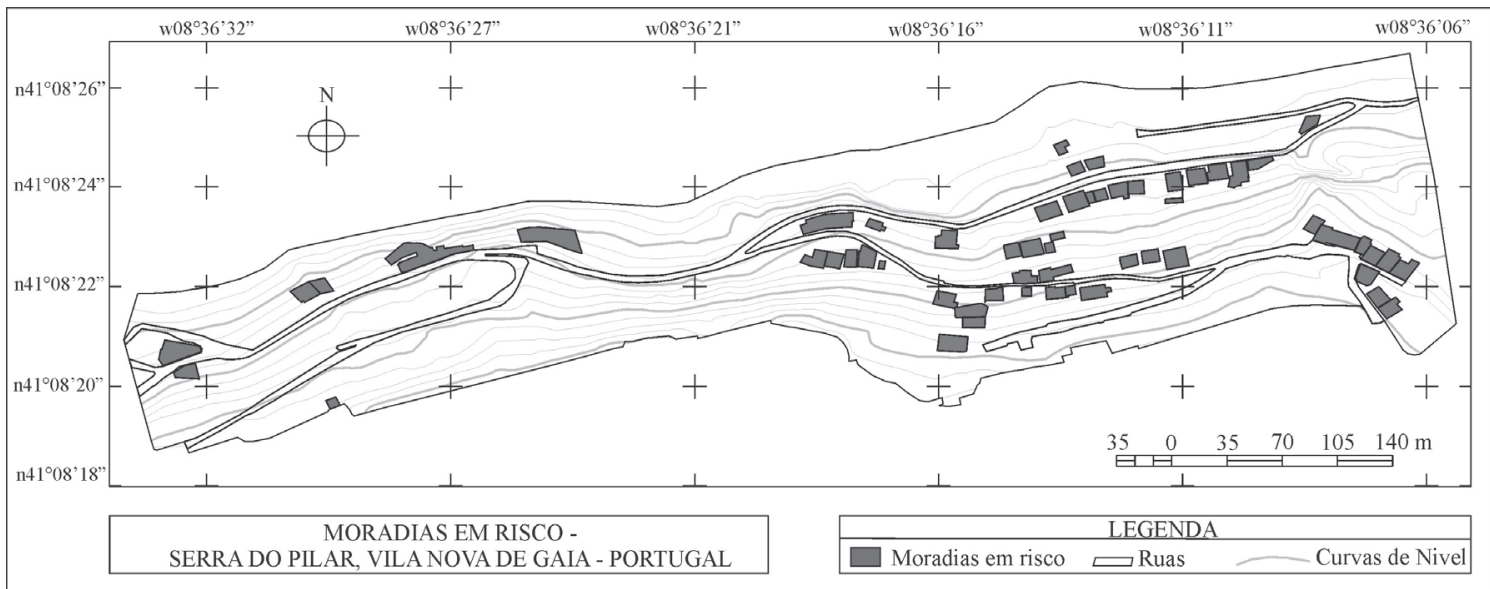

Figura 3 - Mapa base da encosta Serra do Pilar com as moradias e vias.

A rocha granítica exposta na vertente apresenta dois conjuntos de fraturas subverticais que conferem um aspecto colunar. Cortando esse conjunto ocorrem fraturas com mergulho entre 30-50 graus e sentido variado. Além desse conjunto de fraturas tectônicas ocorrem fraturas por alívio de pressão, paralelo à vertente, devido à exposição da rocha granítica à superfície.

Conforme Ribeiro e Pereira (1992, apud NORONHA, 2005), os processos tectônicos apresentam uma fase dita F3, que correspondeu a tensões compressivas máximas com orientação NE-SW. Além de responsável por dobramentos e pelos cisalhamentos NW-SE e ENE-WSW, implicou também fendas de tracção NE-SW e NNE-SSW registadas nomeadamente nos maciços graníticos de duas micas sintectônicos relativamente a F3.

Posteriormente à $\mathrm{F} 3$ atuaram as fases terminais hercínicas, sob a ação de uma tensão compressiva máxima N-S que implicou o rejogo das fraturas geradas, principalmente, durante o período terminal de F3. Foi neste período que o sistema frágil NNE-SSW atingiu maiores proporções. As principais direções de fraturas observadas nos afloramentos graníticos revelam orientação NE-SW (N30 a N60E), que é o mais marcado, e ENE-WSW a NW-SE (N100 a N140E).

A alteração do material rochoso está condicionada aos componentes mineralógicos e ao fraturamento. O predomínio de quartzo e feldspato, além da mica branca, no granito que compõem o substrato na encosta da Serra do Pilar, confere à rocha boa resistência aos processos de intemperismo. $\mathrm{O}$ quartzo com seu alto grau de polimerização da sílica é o mineral primário mais resistente ao intemperismo. A moscovita e feldspato potássico também são relativamente resistentes aos processos superficiais.

Nas rochas cristalinas, a drenagem é dada pela fraturação da rocha. A presença de fraturas abertas facilita a entrada da água em rochas pouco permeáveis, fazendo com que alcance os minerais e provoque sua alteração proporcionando, ao longo do tempo, o avanço do estado de alteração do maciço e intensificando, consequentemente, os riscos na encosta.

A ocorrência de matacões e blocos rochosos imersos no solo e expostos na superfície refletem a forma de alteração das rochas graníticas. A alteração seguindo as fraturas, gera porções centrais menos alteradas formando blocos e matacões imersos no manto de alteração. A ação da erosão que retira as porções alteradas do maciço rochoso expõem os fragmentos de rocha na superfície e pode desencadear a sua instabilização.

O manto de alteração superficial apresenta variação de espessura, formando um saibro arenoso com blocos e matacões de rocha. A vegetação de pequeno e médio porte instala-se nas fraturas e no solo arenoso especialmente onde o escoamento superficial se acumula. A Figura 4 apresenta uma fotografia da vertente ocupada onde pode-se observar as porções com rochas expostas e as áreas de maior alteração do maciço rochoso, que apresenta relativa facilidade de corte, $o$ que permite a instalação das habitações.

\section{Estabilidade da encosta}

A fraturação do maciço granítico representa o aspecto dominante e controlador da dinâmica da escarpa, pois é a partir destas que os processos de alteração se desenvolvem e, além disso, conforme a orientação das fraturas em relação ao corte da escarpa podem ocorrer quedas de rocha.

Nos períodos de maior precipitação, que ocorre normalmente no outono/inverno, aumenta a instabilidade da vertente, devido ao acréscimo na quantidade de água no manto de alteração e consequentemente pelo aumento de peso dos materiais que intensificam as possibilidades de ocorrência de movimentos na vertente. 


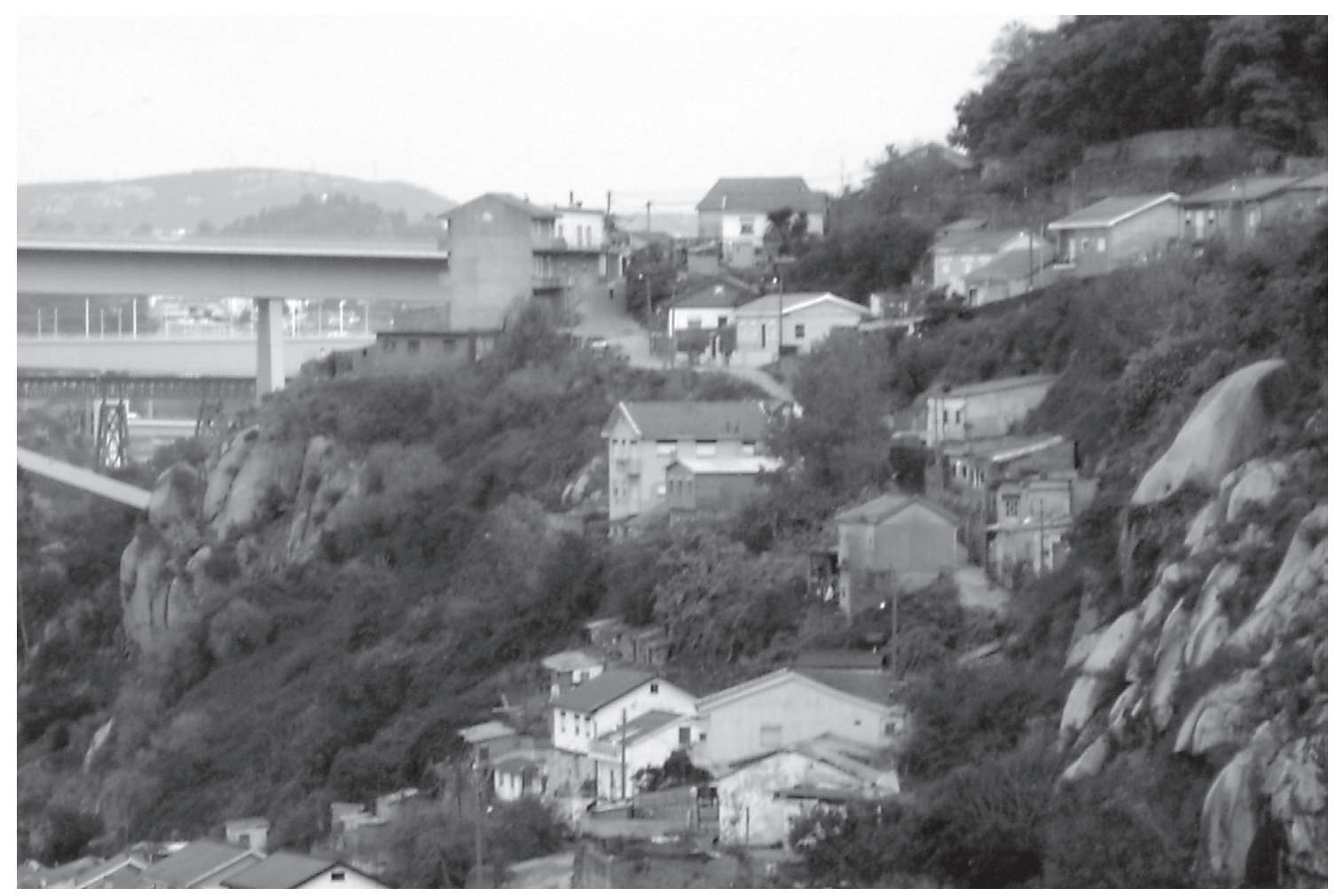

Figura 4 - Exposição da rocha onde observa-se a instalação da vegetação em porções da encosta e moradias localizadas abaixo das rochas (Fonte: Trabalho de Campo, 2008).

$\mathrm{Na}$ área em estudo ocorrem duas situações gerais com características distintas em termos de susceptibilidade a movimentos na vertente: uma situação onde ocorre a exposição de rochas em declives muito acentuados; e outra porção onde ocorre uma concentração de fluxo de água com desenvolvimento de um solo/alterito que permite a fixação de vegetação.

No primeiro caso, a direção e o sentido das fraturas da rocha controlam a susceptibilidade ao risco. Os movimentos de vertente são rápidos e constituídos por fragmentos do maciço rochoso, blocos e matacões. Ocorrem em superfície plana, quando associadas a planos inclinados em relação ao corte, ou em cunha, quando associados à perda de estabilidade das colunas formadas pelos dois sistemas principais de subverticais de fraturação.

A água da precipitação, com sua ação erosiva e exercendo pressão ao percorrer as fraturas, também intensifica os riscos. Além disso, nesta porção, as diferenças de temperatura que ocorrem no inverno, causam dilatação e contração nos materiais rochosos, podendo, em tempo mais longo, induzir a ocorrência de movimento nas vertentes. Blocos e matacões imersos no solo também podem ser indutores de acidentes devido à possibilidade de queda associada à ação erosiva na base e à perda da estabilidade.

A segunda situação envolve a presença de camadas de manto de alteração, com blocos de rocha e vegetação associados. Nesta situação podem ocorrer movimentos rápidos de solos e rocha definidos como deslizamentos. A instabilidade está fortemente associada a períodos de significativa acumulação de água da chuva que provoca o aumento do peso do solo e diminuição da resistência ao cisalhamento, devido a fluxos laminares entre o solo e a rocha.

Nessa parte da escarpa a ocupação é mais concentrada, pois permite o corte e o estabelecimento de patamares aumentando o risco devido à densidade ocupacional. Os movimentos de massa, também, são induzidos pela ação antrópica, sendo a mais importante associada à possibilidade de ruptura de estruturas construídas ou depósitos de entulhos nos pátios das moradias e na própria vertente.

$\mathrm{Na}$ área em estudo também se observam muros de pedra semelhantes aos usados em atividades agrícolas. Estes muros servem para expansão dos terrenos, estabelecendo patamares parciamente aterrados. Essas estruturas podem ser indutoras de movimentos de massa por não haver controle do escoamento das águas pluviais e servidas.

A presença de vegetação de médio porte também foi observada em cortes do terreno que expõem as raízes. Essa situação também pode ser indutora de movimentos na vertente provocados pelo tombamento da vegetação produzido pela ação erosiva no manto de alteração junto às raízes. 
Além disso, pode-se considerar que a forte variação de nível d'água do Rio Douro, em períodos de elevada precipitação na bacia, até os patamares inferiores da ocupação provoca um aumento na capacidade erosiva que age sobre a margem rochosa fraturada, podendo desencadear movimentos de massa.

\section{Discussão sobre as áreas de risco}

O risco pode ser definido pela probabilidade de ocorrência de algum dano a uma população (pessoas ou bens materiais), ou seja, é uma condição potencial de ocorrência de um acidente, podendo ser escrito conforme Carvalho e Galvão (2006), pela fórmula: $\mathrm{R}=\mathrm{H}(\mathrm{fA}) * \mathrm{C}(\mathrm{fV}) * \mathrm{~g}-1$, na qual um determinado nivel de risco $\boldsymbol{R}$ representa a probabilidade $\boldsymbol{H}$ de ocorrer um fenômeno físico em $\boldsymbol{A}$, em local e intervalo de tempo especificos e com características determinadas (localização, dimensões, processos e materiais envolvidos, velocidade e trajectória); causando consequências $\boldsymbol{C}$ (às pessoas, bens elou ao ambiente), em função da vulnerabilidade $\boldsymbol{V}$ dos elementos expostos; podendo ser modificado pelo grau de gestão.

O primeiro termo da equação representa a probabilidade de ocorrência do fenômeno físico (A) responsável pela situação de risco.

Neste contexto, as vertentes que ocorrem ao longo do Rio Douro, em Porto e Vila Nova de Gaia, se constituem em áreas de risco de ocorrência de acidentes naturais. Na Serra do Pilar localizam-se pelo menos 60 moradias com variados níveis de risco associados a deslizamentos, queda e rolamento de rocha e rocha/solo.

As moradias estão localizadas principalmente na porção leste da encosta, onde a vertente apresenta forma côncava e existem patamares que facilitam a construção das residências. Na porção noroeste ocorrem algumas moradias em risco, entretanto, a vertente apresenta forma retilínea, coforme pode ser observado na Figura 5.

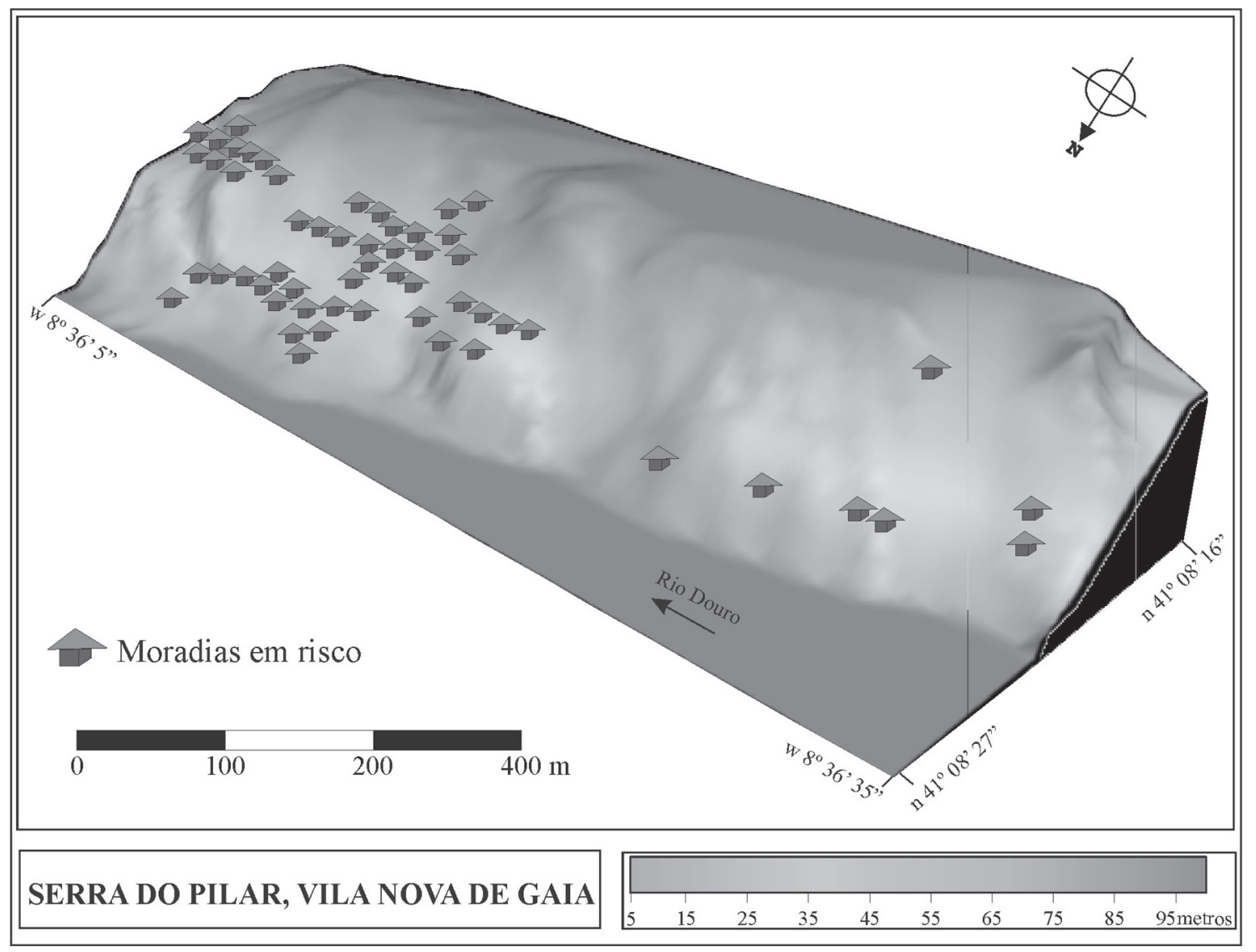

Figura 5 - Modelo digital de terreno com as moradias em risco de acidentes na encosta.

Na Figuras 6 observa-se a parte a leste da área com forma côncava onde se verifica uma densificação das habitações. Nessa porção ocorre concentração de fluxo das águas superficiais, sendo uma zona onde a fraturação do maciço granítico é mais pronunciado, permitindo desenvolvimento de um solo/alterito e desenvolvimento de vegetação. 


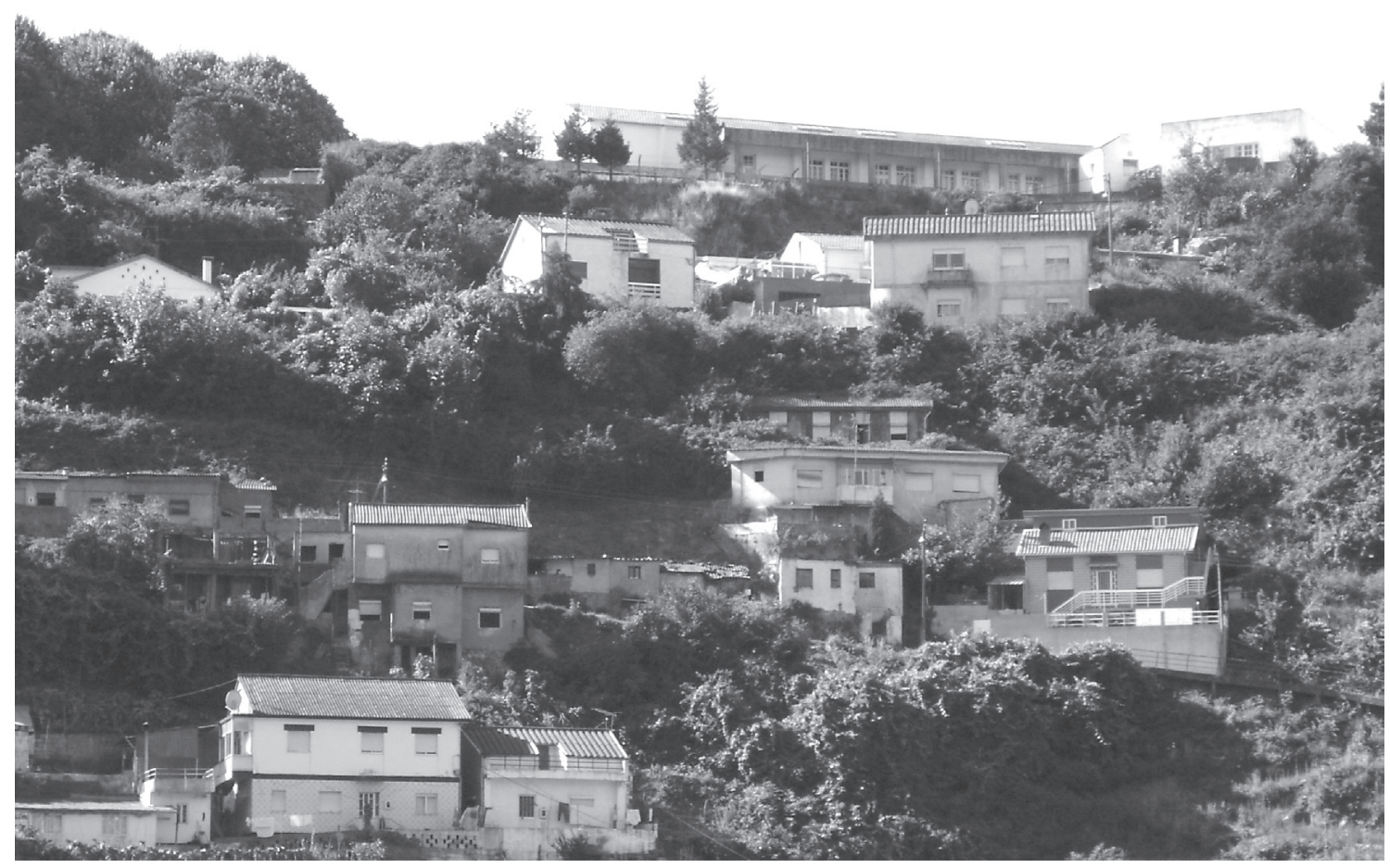

Figura 6 - Fotografia de frente onde pode-se observar uma porção côncava da encosta e as habitações ocupando diferentes patamares (Fonte: Trabalho de Campo, 2008).

Verifica-se também pelo menos seis patamares de corte na frente e atrás das moradias, que foram realizados para a instalação das habitações. Estes cortes juntamente com o acúmulo de água pluvial e de esgoto, a presença de entulhos, muros e pequenas construções podem se constituir em indutores da ocorrência de processos na vertente.

Nas escapas ao longo do Rio Douro, onde está localizada a Serra do Pilar, têm-se registrado diversos acidentes. Em 2006, um deslizamento de terras danificou casas desalojando seis pessoas e deixou um ferido. $\mathrm{O}$ acidente ocorreu, conforme informações da Defesa Civil, em uma escarpa da Rua Cabo Simão. O material mobilizado era constituído por entulhos, lixo, vegetação e blocos de rochas.

O segundo componente da equação está relacionado às consequências. Problemas de mesma natureza e dimensão afetam de modo bem diferente uma parte da cidade formal de outra parte com ocupação precária, desorganizada espacialmente e desprovida de infraestrutura adequada.

$\mathrm{Na}$ área, as situações de risco grave ocorrem onde a densidade ocupacional é mais elevada. Esse situação tem uma relação de causa e efeito, pois quanto maior o número de moradias, maiores serão as consequências e maior o risco, uma vez que as perdas sociais e econômicas tornam-se mais elevadas. $\mathrm{O}$ maior adensamento populacional também aumenta as modificações na vertente o que incrementa a susceptibilidade.

$\mathrm{O}$ último fator da equação é a gestão do risco. Ocorre uma diminuição dos riscos à medida que aumenta a gestão.
Como observa Wenger (1978), o tipo de organização social pré-impacto exerce uma influência decisiva no grau de vulnerabilidade das populações a eventos naturais. As situações encontradas no contexto pós-desastres podem ser entendidas como extensão das condições organizativas e sociais vigentes na fase pré-desastre.

Na Serra do Pilar são conhecidos os riscos e, nas últimas décadas, conforme informações no Concelho, foram realizadas algumas ações no bairro, no âmbito do Programa Especial de Realojamento, como o calçamento de ruas. Em 2005 , foi realizado o gradeamento de suporte na parte superior da escarpa com cerca de 50 metros e foram instalados coletores de lixo. Nos trabalhos de campo observou-se ao longo da escarpa de rocha a instabilização de parte do maciço através da pregagem ou ancoragens.

Ainda, conforme informações do município, existe um plano de emergência para a área. Entretanto, este plano é praticamente desconhecido pela população local. Além disso, a relação estabelecida entre o poder público e a comunidade não tem sido das melhores, especialmente devido à ilegalidade da ocupação. Dessa forma a população apresenta resistência ao desenvolvimento de trabalhos de pesquisa que avaliem as condições de risco na vertente.

Outra observação importante e preocupante é a falta da percepção do risco por parte das pessoas que vivem no local, baseada no fato do tempo que habitam a escarpa e o número de ocorrência de acidentes. 


\section{Considerações finais}

A relação homem-meio/sociedade-natureza é fundamental para a compreensão dos mecanismos de gestão e intervenção do território.

Desta maneira, é fundamental que os estudos considerem de forma mais sistemática os fatores sociais e tecnológicos ao lado dos elementos naturais, havendo uma abertura para o uso do conceito de vulnerabilidade associado às estruturas socioeconômicas e político-institucionais.

A escarpa da Serra do Pilar apresenta susceptibilidade principalmente associada ao forte declive incrementado devido a ocupação. As características da rocha e do solo/ alterito gerado permitem cortes subverticais sem originar um significativo plano de descontinuidade. Entretanto, o aumento das intervenções, sem planejamento, nas áreas onde o escoamento é concentrado pode levar à indução de movimentos na vertente.

A falta de um trabalho organizado com a comunidade onde seja possível discutir formas de convivência com risco e estabelecer condições mais organizadas de ocupação com regras para as construções e intervenções, além da baixa percepção da população face ao risco são fatores que incrementam o desenvolvimento de processos individuais ou de massa nesta vertente.

O controle da drenagem pluvial precário e a continuidade de construções sem um planejamento e reorganização do espaço adequado são situações que levam a um aumento dos conflitos em curto período.

É necessário a execução de um plano de intervenções estruturais voltado para a redução ou a erradicação dos riscos concomitante com uma discussão com a comunidade, buscando uma organização comunitária participativa nos projetos de monitoração permanente e prevenção de acidentes.

\section{Referências bibliográficas}

CAMARA, G.; SOUZA, R. C. M.; FREITAS, U. M.; GARRIDO, J. SPRING: Integrating remote sensing and GIS by objectoriented data modelling. Computers \& Graphics, 20: (3) 395403, May-Jun 1996.
CARVALHO, C. S; GALVÃO, T (org). Ministério das Cidades/ Cities Alliance. Prevenção de riscos de deslizamentos em encostas: Guia para elaboração de políticas municipais. Brasília: Ministério das Cidades; Cities Alliance, 2006. 111 p.

INPE. SPRING: Sistema de Processamento de Informações Georreferenciadas. Disponível em: <http://www.dpi.inpe.br/ spring/>. Acesso em: 18 dez. 2008.

GOLDEN SOFTWARE INC. Surfer 8.0 for Windows. Users Guide. 2002. 340 p.

GOOGLE. Google Earth, Version 4.0.1693 (beta). 2006. USA.

KOBIYAMA, M. et al. Prevenção de desastres naturais: conceitos básicos. Curitiba: Organic Trading, 2006.

MATOS, F. L. de. A construção clandestina em Vila Nova de Gaia - O caso dos bairros do Picão e da Madalena Nascente. Revista da Faculdade de Letras - Geografia - I Série, Vol.VI, Porto, 1990. p. 149-280.

MINISTÉRIO DAS CIDADES. Prevenção de riscos de deslizamentos em encostas: guia para elaboração de políticas municipais. Brasília, 2006. cap. 3.

NORONHA, F. Geologia, Tectónica, Geomorfologia e Sismicidade da Cidade do Porto. Departamento de Geologia da Faculdade de Ciências - Universidade do Porto. Carta Geotécnica do Porto - WORKSHOP - Maio, 2005.

OGURA, A.; MACEDO, E. S. Procesos y riesgos geologicos. In: II Curso internacional de aspectos geologicos de protección ambiental. 2002. Disponível em: <http://www.unesco.org.uy/ geo/campinaspdf/9procesos.pdf.> Acesso em: 9 jun. 2009.

SANTOS, M. Tendências da urbanização brasileira do século XX. In CARLOS, Ana F.A. (Org.) Os caminhos da reflexão sobre a cidade e o urbano. São Paulo: 2 ed., 1994., 342 p.

WENGER, D. Community response to disaster: functional and structural alterations. In: QUARENTELLI, E.L. (org) Disaster: theory and research. Sage, NY, 1978. p.17-47.

VEYRET, Y. Os riscos: o homem como agressor e vítima do meio ambiente. Tradução: Dílson Ferreira da Cruz. São Paulo: Contexto, 2007. p. 11-38. 